\title{
Influence of indentation size and spacing on statistical phase analysis via high-speed nanoindentation mapping of metal alloys
}

\author{
Hossein Besharatloo ${ }^{1,2}$, Jeffrey M. Wheeler ${ }^{3, a)}$ (1) \\ ${ }^{1}$ CIEFMA - Department of Materials Science and Metallurgical Engineering, EEBE, Technical University of Catalonia-BarcelonaTech, \\ 08019 Barcelona, Spain \\ ${ }^{2}$ Barcelona Research Center in Multiscale Science and Engineering, Technical University of Catalonia-BarcelonaTech, 08019 Barcelona, Spain \\ ${ }^{3}$ Laboratory for Nanometallurgy, Department of Materials Science, ETH Zürich, Vladimir-Prelog-Weg 5, 8093 Zurich, Switzerland \\ a) Address all correspondence to this author. e-mail: jeff.wheeler@mat.ethz.ch \\ Received: 15 December 2020; accepted: 15 April 2021; published online: 26 April 2021
}

\begin{abstract}
The development of high-speed nanoindentation has enabled the acquisition of mechanical property maps over square millimeters of area with micron-scale resolution in reasonable amounts of time. This provides rich datasets which contain morphological and statistical data on the variation of mechanical properties in a microstructure. However, the influences of the indentation size and the deconvolution method employed on the extracted phase properties remain unclear. In this work, a range of depth/ spacing increments was explored on two different materials systems, an Al-Cu eutectic alloy and a duplex stainless steel, representing an 'easy' and a 'hard' case for statistical deconvolution, respectively. A total of $\sim 500,000$ indentations were performed. A variety of statistical analyses were then employed and compared: the 1D analysis of Ulm et al. using 2 and 3 phases, a 2D rotated Gaussian fit, K-means clustering, and a visual comparison to 2D histograms. This revealed several different sensitivities of the deconvolution methods to various types of error in phase identification.
\end{abstract}

\section{Introduction}

The development of instrumented nanoindentation coupled with the Oliver and Pharr analysis [1] in the 1990s allowed a new era of automated, local mechanical property measurement. Over the last 30 years, numerous applications of this technique have been developed, and many new scientific discoveries have been enabled as a consequence, e.g., the indentation size effect (ISE) [2]. Two of the developed applications for nanoindentation are mapping [3] and statistical property extraction [4]. Both of these techniques use large grids of indentations, but they consider the data in different ways. Indentation mapping, or cartography, considers the variation of the measured properties over a two-dimensional surface, whereas statistical extraction assumes a number of discrete phases and fits their distributions within a property space to determine the fraction, average value, and variation of each separate, constitutive phase while ignoring the positions of the indents in the Cartesian surface.
Initially, both of these techniques required a significant amount of experimental time due to the large numbers of indents required. However, advances in instrumentation and electronics have now enabled the speed of indentation to be increased approximately 100 times, such that many thousands of indentations can now easily be performed within an hour [5-7]. This makes both techniques simultaneously more accessible and thus more popular with numerous applications emerging in the recent literature on a variety of materials: cements $[8,9]$, hardmetals [6, 10, 11], Ni-Fe meteorites [12], titanium [13], duplex [14] and tool steels [15], and thermal barrier coatings [16].

The increasing popularity of high-speed indentation mapping makes the analysis methods for the large volumes of data emerging from the technique increasingly important. Primarily, this has been conducted using the statistical property analysis technique proposed by Ulm et al. [4, 17-19]. However, some additional techniques have also recently been applied: K-means cluster analysis [16] and machine learning [20,21]. Both of 
these techniques also allow the spatial positions of the indents to be considered as an additional dimension during the analysis allowing visualizing of the clusters within the maps. Correlative techniques combining nanoindentation mapping with analytical electron microscopy have also recently been demonstrated using energy-dispersive X-ray spectroscopy (EDX) on meteorites [12] and electron back-scattered diffraction (EBSD) on titanium [13]. These correlative techniques also allow extra dimensions to be added to the dataset, enriching it, and allowing easier discrimination between either discrete phases or smooth orientation/compositional gradients. However, these correlative techniques are still emerging and have not yet achieved widespread adoption.

In this work, we investigate the influence of indentation size and spacing on the statistical analysis of high-speed nanoindentation maps on two different two-phase materials: an $\mathrm{Al}-\mathrm{Cu}$ eutectic alloy and a duplex stainless steel (DSS). These present two distinctly different challenges for the deconvolution. The phases in $\mathrm{Al}-\mathrm{Cu}$ eutectic have strongly varying mechanical properties but a finely mixed microstructure, and the DSS has only slightly different mechanical properties but a more discrete microstructure. Thus, both systems produce convoluted statistical responses with overlapping property distributions but in different ways. These both represent greater deconvolution challenges than the previous investigation using $K$-means by Vignesh et al. [16] on superalloy bond coat phases which displayed a wide disparity in mechanical properties and discrete phase boundaries. We explore these differences in each system using indentation maps of 40,000 indentations performed with four different target indentation depths $(100,200,350$, and $500 \mathrm{~nm}$ ), while maintaining the suggested [22] indentation spacing/depth ratio of 10 , to observe the resulting variation in property distributions. These are then analyzed using the $1 \mathrm{D}$ analysis of Ulm et al. [4], multivariate K-means cluster analysis [23], and a 2D Gaussian peak fitting method to compare and contrast the different deconvolution methods. Previous works in the literature have only used a single deconvolution method, rather than several. The authors believe this work to be the first to compare the effectiveness of the various deconvolution methods and the first to systematically perform multiphase maps at a range of indentation depths and spacings.

\section{Results}

\section{Conventional nanoindentation}

Conventional nanoindentation testing was performed on each individual phase (detected by EBSD) of the investigated samples. The continuous stiffness measurement (CSM) method was used so that the elastic modulus $(E)$ and hardness $(H)$ could be continuously determined at each indentation depth $(h)$ up to the maximum applied load $(P)$. The obtained results of both studied samples are shown in Fig. 1. $P-h$ curves of different imprints (performed on each constitutive phase), as well as their corresponding $H$ and $E$ curves are plotted as a function of depth for both the Al-Cu eutectic and the DSS samples.

The obtained $P-h$ curves of individual phases within the $\mathrm{Al}-\mathrm{Cu}$ eutectic sample demonstrate distinct mechanical responses. The mechanical properties of the theta $\left(\mathrm{Al}_{2} \mathrm{Cu}\right)$ and aluminum phase are show significantly different magnitudes, with the hardness values showing greater disparity compared with $E$ curves. These results are consistent with those recently observed on an $\mathrm{Al}-\mathrm{Cu}$ diffusion couple investigated by the same methods [24]. The hardness and elastic modulus values as a function of indentation depth show stable behavior during indentation for both phases. Indicating that there is no significant indentation size effect in this material, which is unsurprising given its complex, constrained microstructure. In materials like nanocrystalline metals or the fine-structured dendritic $\mathrm{Al}-\mathrm{Cu}$ eutectic tested here, the internal length scale is already quite small, so the external size of the indentation has a relatively small effect [25].

The obtained $P-h$ curves from nanoindentations performed on austenite $(\gamma)$ and ferrite $(\alpha)$ phase display rather different behavior from the eutectic alloy: they almost completely overlap. This reveals the high degree of similarity in the micromechanical response of the phases within this DSS samples. However, the elastic modulus vs. depth curves for individual phases of DSS clearly indicate a higher elastic modulus for the a ferrite phase compared with the $\gamma$ austenite phase. In terms of hardness, the obtained results are quite close for the first $200 \mathrm{~nm}$, while the austenite phase is slightly harder than ferrite phase. Thereafter, no clear difference can be discerned between phases, and the curves converge at higher penetration depth. Moreover, a notable ISE emerges clearly in hardness curves for all imprints before $~ 300 \mathrm{~nm}$ penetration depth.

\section{Mechanical phase maps}

Conventional indentation testing provides us with a clear impression of the mechanical properties of each phase at different penetration depths. With the mechanical property evolution with penetration depth shown in Fig. 1 in mind, indentation mapping was performed using the NanoBlitz technique using a range of target loads and indentation spacings on both Al-Cu eutectic and DSS samples. A full description of the testing method and choice of applied loads and indentation spacings are provided in "Nanoindentation" section. In short, the applied loads were chosen to ensure that indentations depths were close to or below a target value $(10 \%$ of the spacing increment) to prevent overlapping indentations. These maps provide us information about the mechanical 

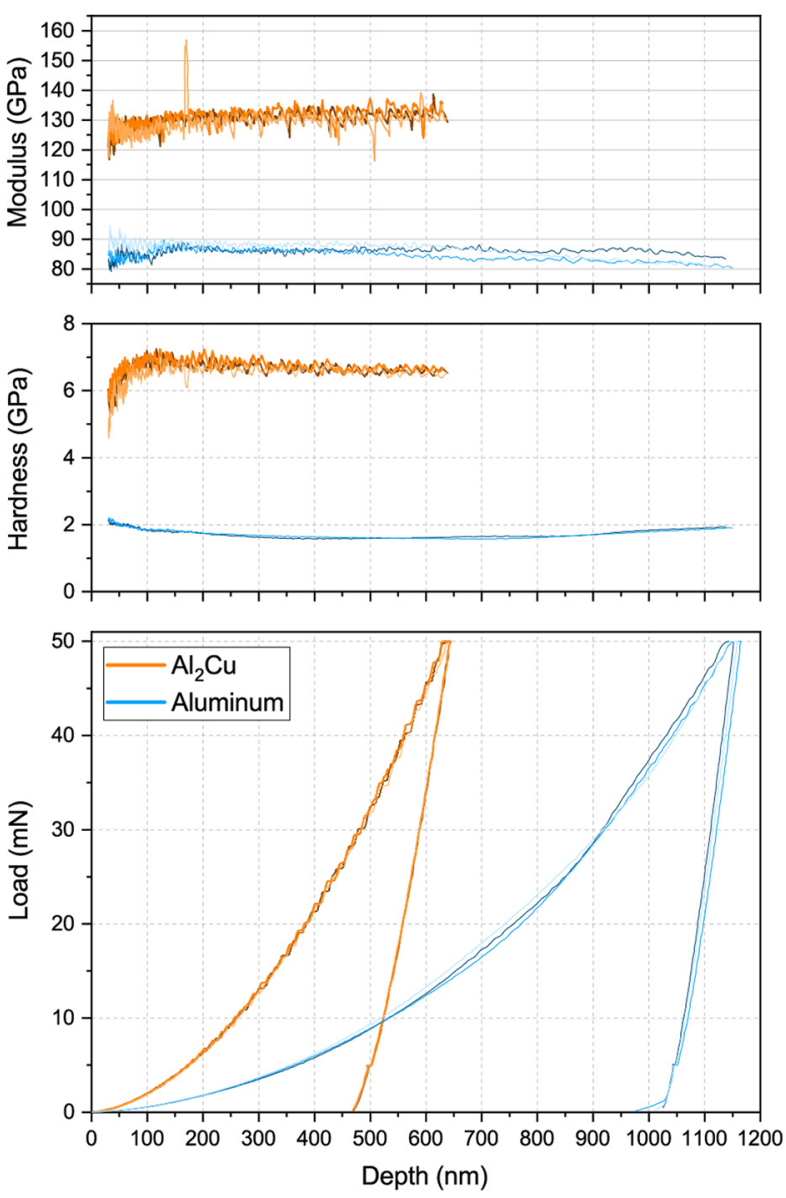

Al-Cu Eutectic
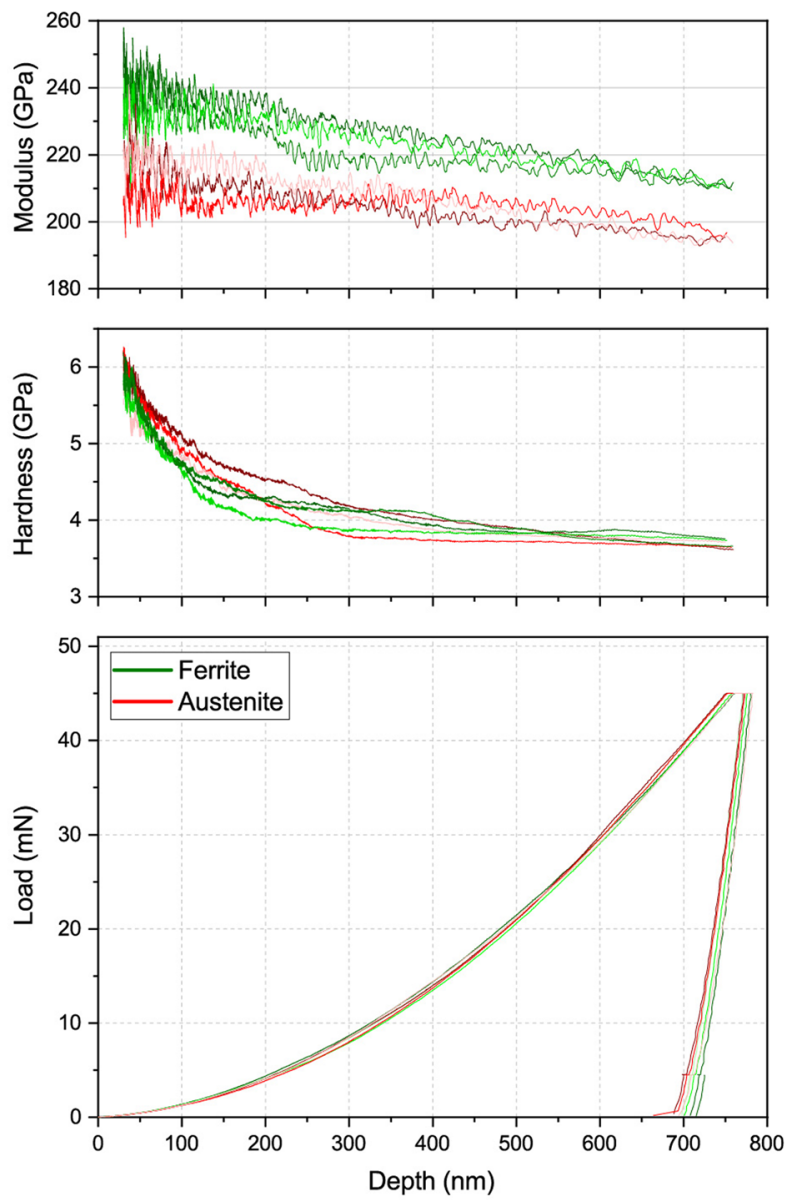

Duplex Stainess Steel

Figure 1: Representative load-displacement curves acquired during CSM indentation to 50 and $45 \mathrm{mN}$ loads on AI-Cu eutectic and DSS samples, respectively. Corresponding elastic modulus and hardness curves are presented above.

properties $(H$ and $E)$ of each constitutive phase at depths $\leq$ the target value. Moreover, the influence of spacing and ISE can be analyzed by observing the resulting map morphologies and by implementing statistical analysis on the resulting data, which will be discussed in detail later. Figure 2 shows the obtained $H$ and $E$ maps at different spacings for both studied samples.

The indentation maps performed on Al-Cu eutectic sample show very strong differentiation between the two phases. As expected from the individual CSM indentation data, the $H$ map shows better distinction between theta and aluminum phases. However, the resolution of maps decreases with the increase in spacing increment (or step size) between imprints. In this case, the step size is roughly the size of the indentation plastic zone in the softer phase, so that the resolution is the maximum allowed for the indentation depth [22]. Regarding the $E$ maps, an apparent increase in the elastic modulus values of the aluminum phase is observed for the maps performed at 3.5 and $5 \mu \mathrm{m}$ spacings. This phenomenon might be attributed to the neighboring/overlapping effect of fine theta phase dendrites on elastic modulus of aluminum phase at high penetration depth.

In the case of the DSS sample, in general, the elastic modulus maps present better visual distinction between austenite and ferrite phases than the $H$ maps at all spacing increments. Their values are similar to those obtained from individual indentations on each phase obtained by the CSM technique, but a general increase in $E$ map values with indentation spacing/depth is notable in this sample. This is possibly due to the influence of pile-up around indentations. However, in the hardness $H$ maps, it can be seen that austenite and ferrite phases can be best distinguished in the map performed at $2 \mu \mathrm{m}$ spacing between imprints. The obtained hardness maps also clearly display an ISE, where $H$ values decrease with increasing penetration depth. A similar but slightly stronger trend can also be observed in the $E$ maps with increasing spacings. Furthermore, in agreement with CSM indentations, the austenite $(\gamma)$ phase displays higher hardness and lower elastic modulus compared with the ferrite $(\alpha)$ phase. More information about the correlation between the mechanical 

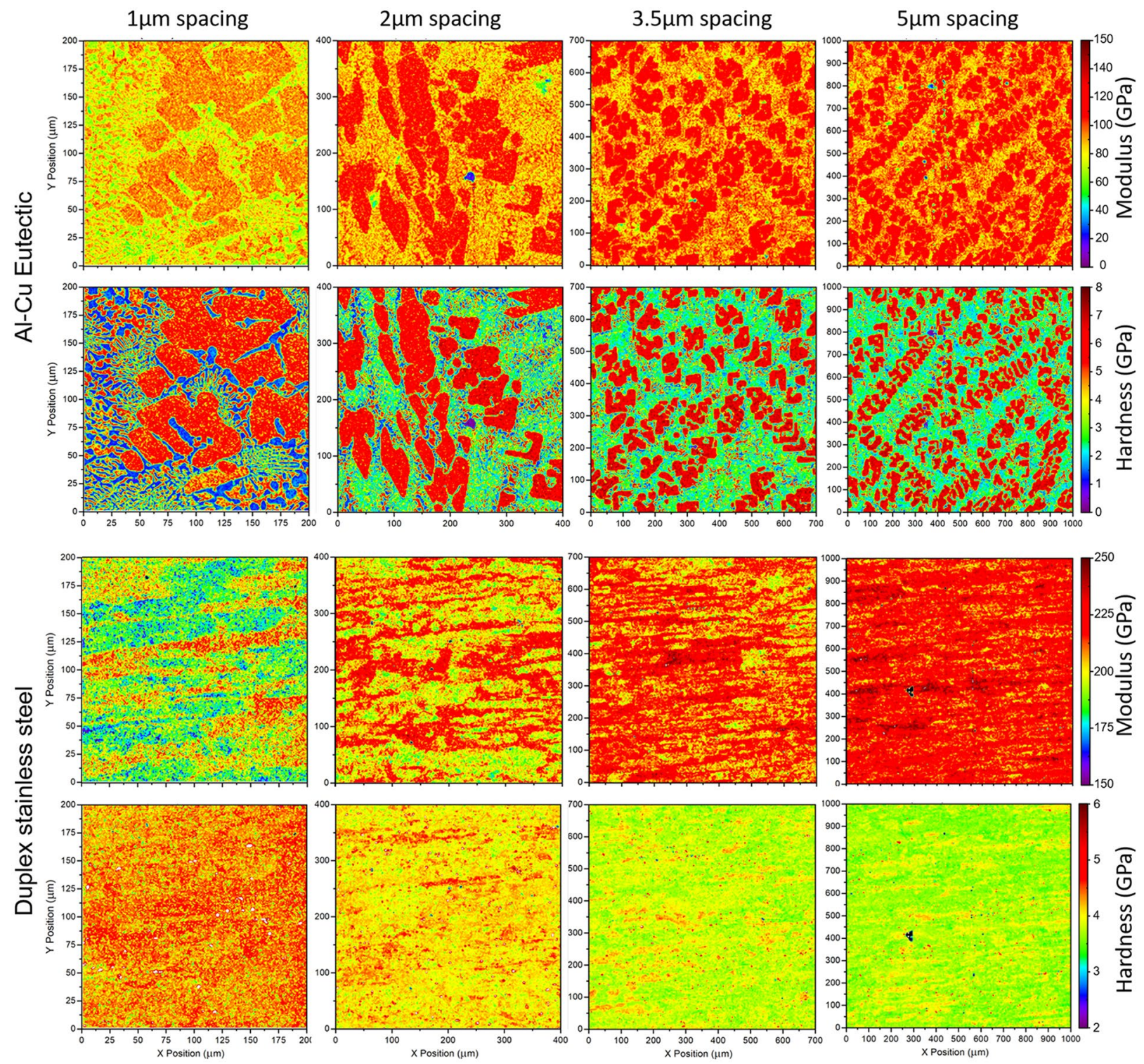

Figure 2: $\mathrm{H}$ and $\mathrm{E}$ maps obtained from performed indentations maps (40,000 per condition) on Al-Cu eutectic and DSS samples at different spacing increments.

properties and the phases in DSS materials at different processing steps is provided elsewhere [14].

Figure 3 displays secondary electron micrographs of the regions mapped with a $1 \mu \mathrm{m}$ spacing on both samples. The micrograph of the $\mathrm{Al}-\mathrm{Cu}$ eutectic displays excellent visual correlation with its corresponding $H$ and $E$ maps in Fig. 2, due to strong contrast between the $\mathrm{Al}$ metal and $\mathrm{Al}_{2} \mathrm{Cu}$ intermetallic phases. The difference in indentation depth in these soft and hard phases is also readily visible, with the $\sim 4 \times$ harder $\mathrm{Al}_{2} \mathrm{Cu}$ phase relatively faint impressions. By comparison, the DSS sample shows little contrast between the austenite and ferrite phases, as expected in this imaging mode, with only some slight grain contrast and the topology of the indentation grid visible.
As shown in this section, mechanical property maps might be considered as an effective way to mechanically distinguish the phases in complex microstructures. However, the functionality of mechanical property maps of this type is dependent on several factors: surface roughness, disparity in mechanical properties of probed phases, penetration depth, and spacing between imprints. Moreover, mechanical property maps might mainly be considered as a qualitative, visual method to mechanically distinguish the individual phases of multiphase materials to provide guidance for subsequent analytical investigations. In order to achieve a quantitative evaluation of the mechanical properties of individual constitutive phases, statistical deconvolution of the massive indentation datasets must be performed. 

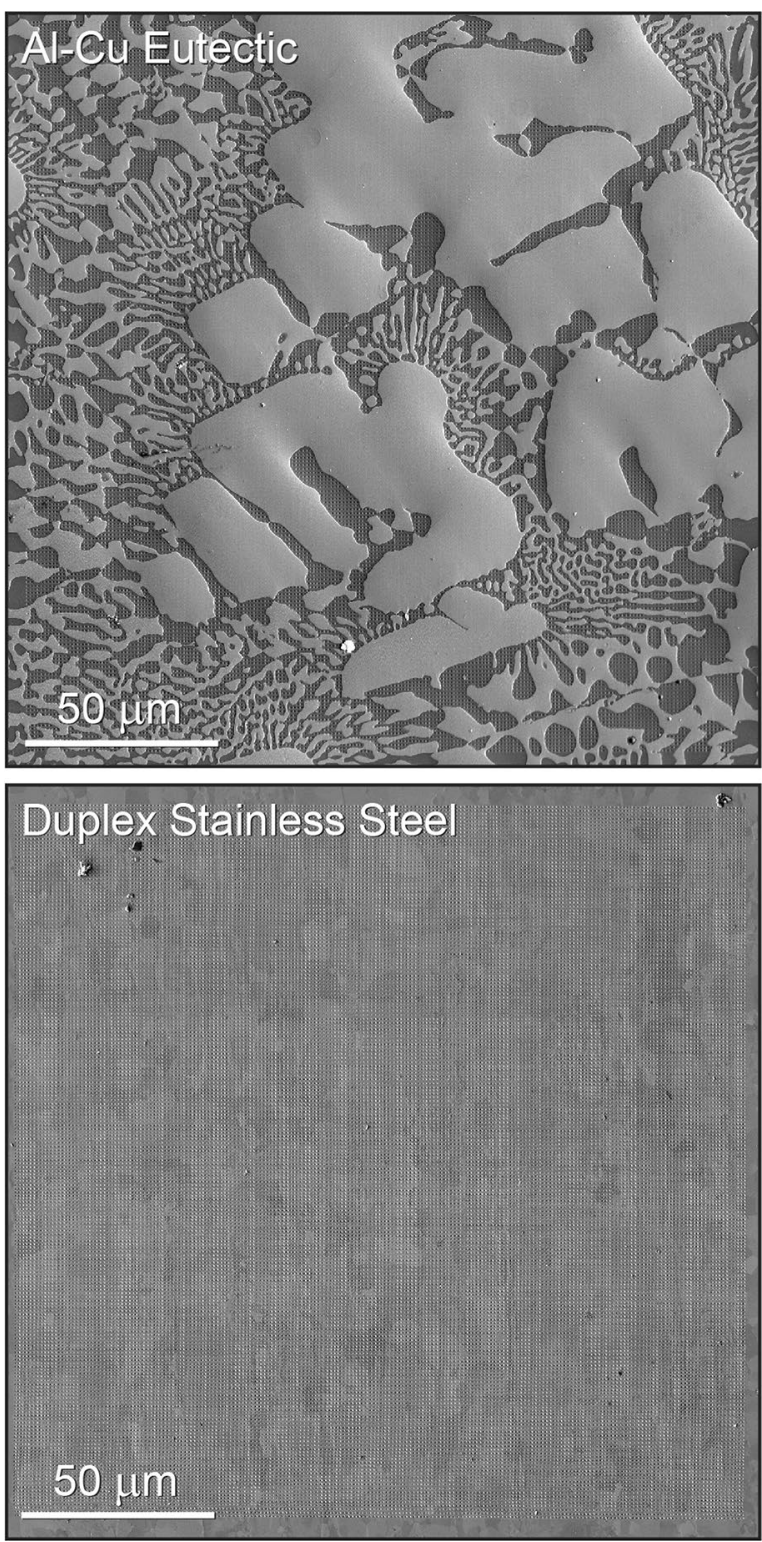

Figure 3: Secondary electron micrographs of the $200 \times 200$ indentation grids performed with a $1 \mu \mathrm{m}$ spacing on the $\mathrm{Al}-\mathrm{Cu}$ eutectic and duplex stainless steel.

\section{Discussion}

\section{H/E ratio maps}

The mechanical property maps presented and discussed in the previous section ("Mechanical phase maps" section) demonstrate the ability of these types of maps to differentiate between different phases. The results for the $\mathrm{Al}-\mathrm{Cu}$ eutectic alloy sample are particularly crisp and distinct representations of the beautiful dendritic microstructure. However, in the case of DSS, the austenite and ferrite phases could be only somewhat distinguished in the $H$ and $E$ maps (Fig. 2).

Indentation hardness is a hybrid measure of the reversible (elastic) and irreversible (plastic) deformation and the indenter geometry [26]. This implies the hardness maps are intrinsically convoluted with the modulus maps, so it is desirable to extract a parameter which more purely describes the plasticity of the material. The $H / E$ ratio is such a measure, which describes the resistance of a material to irreversible deformation. High hardness materials with low stiffness (high $H / E$ ) are more likely to deform purely elastically, while soft materials with high stiffness (low $H / E$ ) are more likely to behave purely plastically. The $H / E$ ratio is often used to describe a "plasticity index" in the fields of tribology and fracture mechanics [27]. Using dimensional analysis and finite element calculations, Cheng and Cheng [28] were able to demonstrate a strong relationship between the $H / E$ ratio and the plastic fraction of the total energy of indentation. In short, the $H / E$ ratio is a measure of how plastic an indentation is with the influence of its modulus removed.

Therefore, as a preliminary analysis step, in addition to $H$ and $E$ maps, $H / E$ ratio maps were plotted for each condition. As shown in Fig. 4 and in previous work [12], H/E ratio maps provide superior contrast between phases for both samples. The difference between the $H / E$ ratio and the $H$ and $E$ maps is more pronounced for the DSS sample. Therefore, it can be derived that, although $H$ and $E$ represent different mechanical phenomena, they are interrelated in such a way that the corresponding $H / E$ ratio for each phase reveals more reliable and comparable values [29], similar to $S^{2} / P$. Hence, $H / E$ ratio offers better resolution to discriminate the mechanical response of the constitutive phases of DSSs, in which the austenitic phase demonstrates a higher $H / E$ ratio compared with the ferritic phase.

\section{D histograms and statistical analysis of $\mathrm{Al}-\mathrm{Cu}$ Eutectic indentation maps}

In order to further develop the concepts of the interrelationship between $H$ and $E$ values, 2D histogram plots are utilized to display the relative magnitudes of the obtained $H$ and $E$ values over the entire mapped region simultaneously. Figures 5 and 6 display the 2D histograms for the eutectic $\mathrm{Al}-\mathrm{Cu}$ and the duplex stainless steel, respectively, at each spacing increment. The color of each pixel represents the number of indentations that are included within a range of $H$ and $E$, which is defined as a $2 \mathrm{D}$ bin size. Values of only 1 indent are shown in light gray to minimize the visual impact of outliers, and higher indentation numbers are shown with a shaded gradient from darker red tones to yellow-white peaks at the highest values in each histogram. These are therefore arbitrary units, depending on the number of total indentations performed. In this study, 40,000 indentations were performed at each spacing/depth increment, so typical peak values for the histograms are between 75 and 200 indentations. These figures offer a simple visual method to evaluate 'hot spots' in the indentation property space which statistically correspond to individual phases. As shown in previous 

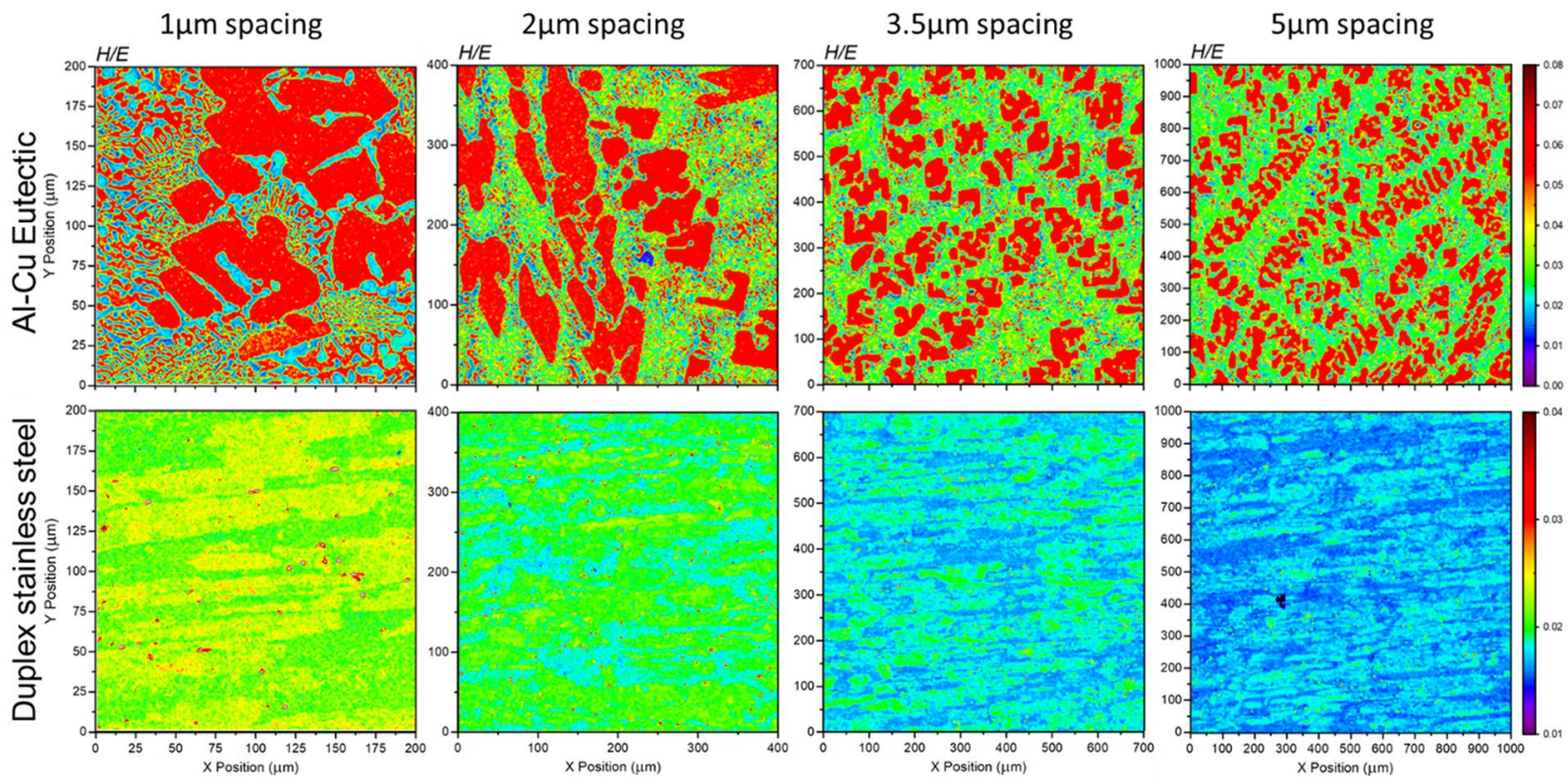

Figure 4: $\mathrm{H} / \mathrm{E}$ ratio maps obtained from nanoindentation maps performed on $\mathrm{Al}-\mathrm{Cu}$ eutectic and duplex stainless steel samples at different spacing increments.

work [14], these 'peaks' in the 2D histograms often take the form of elliptical, normal distributions which are elongated along the direction of the $H / E$ ratio.

Figure 5 displays the $2 \mathrm{D}$ histograms measured on the $\mathrm{Al}-\mathrm{Cu}$ eutectic sample. At least two populations can be easily distinguished in all conditions, corresponding to the aluminum and $\mathrm{Al}_{2} \mathrm{Cu}$, or Theta $(\theta)$, phases and mixtures of the two. As observed in the literature and Fig. 1, the Theta phase has significantly higher hardness corresponding to the upper peak, while aluminum and mixed $\mathrm{Al}+\mathrm{Al}_{2} \mathrm{Cu}$ regions correspond to the lower hardness peak/ cluster. The positions and shapes of these peaks are observed to shift significantly with the variation in indentation spacing and depth. At the shallowest depths and closest spacing $(1 \mu \mathrm{m})$, the two phases are relatively discrete and show strong peaks at values corresponding relatively well to the values of the individual phases. This suggests this indentation depth range corresponds to a plastic zone which is similarly scaled or smaller than the smallest microstructural length scale. This is further shown by the excellent clarity of the features resolved at this spacing in Figs. 2 and 4.

Similar behavior is seen in the histogram from the $2 \mu \mathrm{m}$ spacing map. On further increase to $3.5 \mu \mathrm{m}$ spacing, the peak corresponding to the aluminum phase almost disappears, as it is overwhelmed by the diffuse cloud corresponding to mixed phase indentations which contain both $\mathrm{Al}$ and $\mathrm{Al}_{2} \mathrm{Cu}$. Similar behavior is seen in the histogram from the largest, $5 \mu \mathrm{m}$ spacing increment. This results from the indentation depth range and corresponding plastic zone being too large to fit between the fine $\mathrm{Al}_{2} \mathrm{Cu}$ dendrites, such that a statistical majority of indentations in the Al-rich portion of the microstructure deform both $\mathrm{Al}$ and $\mathrm{Al}_{2} \mathrm{Cu}$.
Although 2D histograms provide a direct, visual method to qualitatively evaluate the mechanically distinct phases, quantitative evaluation of the local mechanical properties of constitutive phases of multiphase materials has always been challenging. In this regard, several different statistical methods have been proposed in the literature to deconvolute the intrinsic properties ( $H$ and $E$ ) of constitutive phases of studied materials. In this work, we applied both of the most popular methods, the 1D Gaussian fitting method of Ulm et al. [4, 17-19] and $K$-means clustering [23], and we propose an additional method, 2D Gaussian fitting. The details of these methods are provided in "Deconvolution methods of mechanical properties" section. The results of these deconvolutions are summarized in Table 1. Standard deviations for 1D and 2D Gaussian methods are extracted from the full-width half maxima of the fitted peaks. However, for $K$-means clustering, only the average distance from the cluster center could be extracted. As this parameter is an average of deviation in both $H$ and $E$, it was omitted from Table 1 as it does not truly compare to the individual deviations in $H$ or $E$ in the other methods. The peak locations or cluster centers corresponding to the mean values of hardness and modulus extracted by each method are plotted on the 2D histograms in Fig. 5.

In the cases of strong peaks in the 2D histograms, all methods agree quite closely and appear to closely correspond to the visually observed peak in the histogram. However, there are some exceptions. In histograms from both 1 and $2 \mu \mathrm{m}$ spacings, the $K$-means clustering correctly identifies the $\mathrm{Al}_{2} \mathrm{Cu}$ phase peak, but it centers the second cluster in between the 'tail' of the $\mathrm{Al}_{2} \mathrm{Cu}$ peak and the $\mathrm{Al}$ peak. This suggests that 

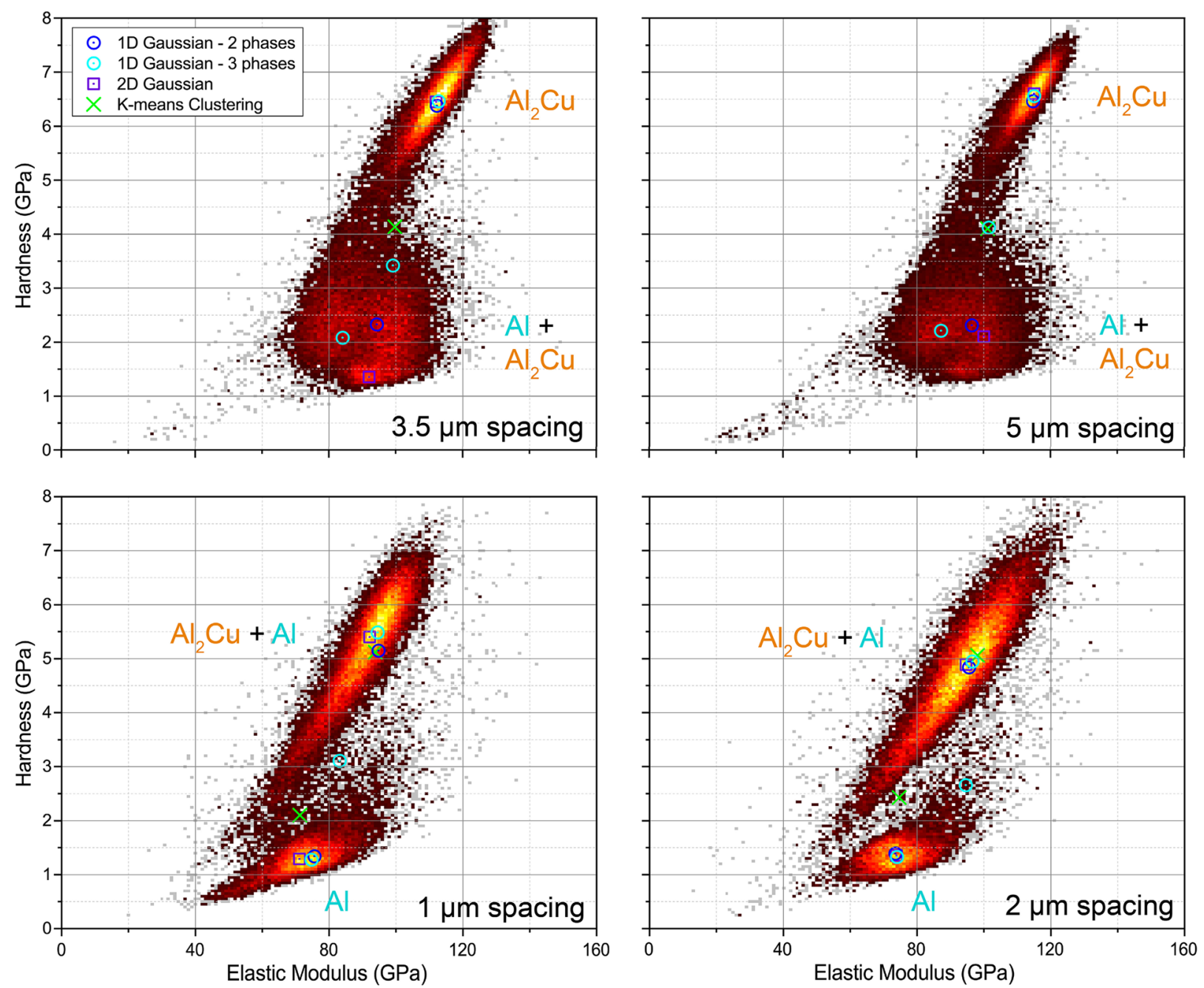

Figure 5: 2D histograms of hardness and elastic modulus data on the Al-Cu eutectic sample from each mapping spacing increment with the locations of the fitting centers from each method labeled.

the algorithm simply took the average value of the lower half of the results and centered the cluster in the middle. This is similar to what is observed for the 'mixed' phase fit by the $1 \mathrm{D}$ Gaussian-3-phase method. Since the 1D Gaussian method only considers each property separately, it overlooks the coupled relationship between $H$ and $E$. Trends in the results projected in only the $H$ dimension fail to capture variation in the $E$ dimension and vice versa. This results in fits which appear to be of high quality by $1 \mathrm{D}$ statistical metrics but correspond to no real features in the $2 \mathrm{D}$ distribution of results observed in the histogram. This is observed for the 'mixed' peak in all spacing/depth increments, as it appears to be centered in the middle of all the data rather than in the 'tail' or 'saddle' connecting the $\mathrm{Al}$ and $\mathrm{Al}_{2} \mathrm{Cu}$ peaks. This highlights the power of the $2 \mathrm{D}$ histogram visualization for this method and illustrates the need for analysis methods which incorporate 2 or more dimensions of the data.
The weaker, irregular cluster of data in the histograms from the 3.5 and $5 \mu \mathrm{m}$ spacings presented a challenge to all the methods. The clusters of data show several subpeaks or lobes which correspond to the $\mathrm{Al}$ phase and $\mathrm{Al}+\mathrm{Al}_{2} \mathrm{Cu}$ mixed regions. At the $3.5 \mu \mathrm{m}$ spacing, the 2D Gaussian method still identifies the $\mathrm{Al}$ peak, while the 1D Gaussian method indicates the center of the mixed region. The 2-phase 1D Gaussian more closely indicates the center than the 3-phase version. Similar behavior is observed in the histograms from the $5 \mu \mathrm{m}$ spacing, but the 2D Gaussian method now also indicates the center of the mixed region.

\section{D histograms and statistical analysis of duplex stainless steel indentation maps}

The analysis and deconvolution of the phase properties of the duplex stainless steel presents several of the same challenges as the Al-Cu eutectic alloy. However, the deconvolution is more 

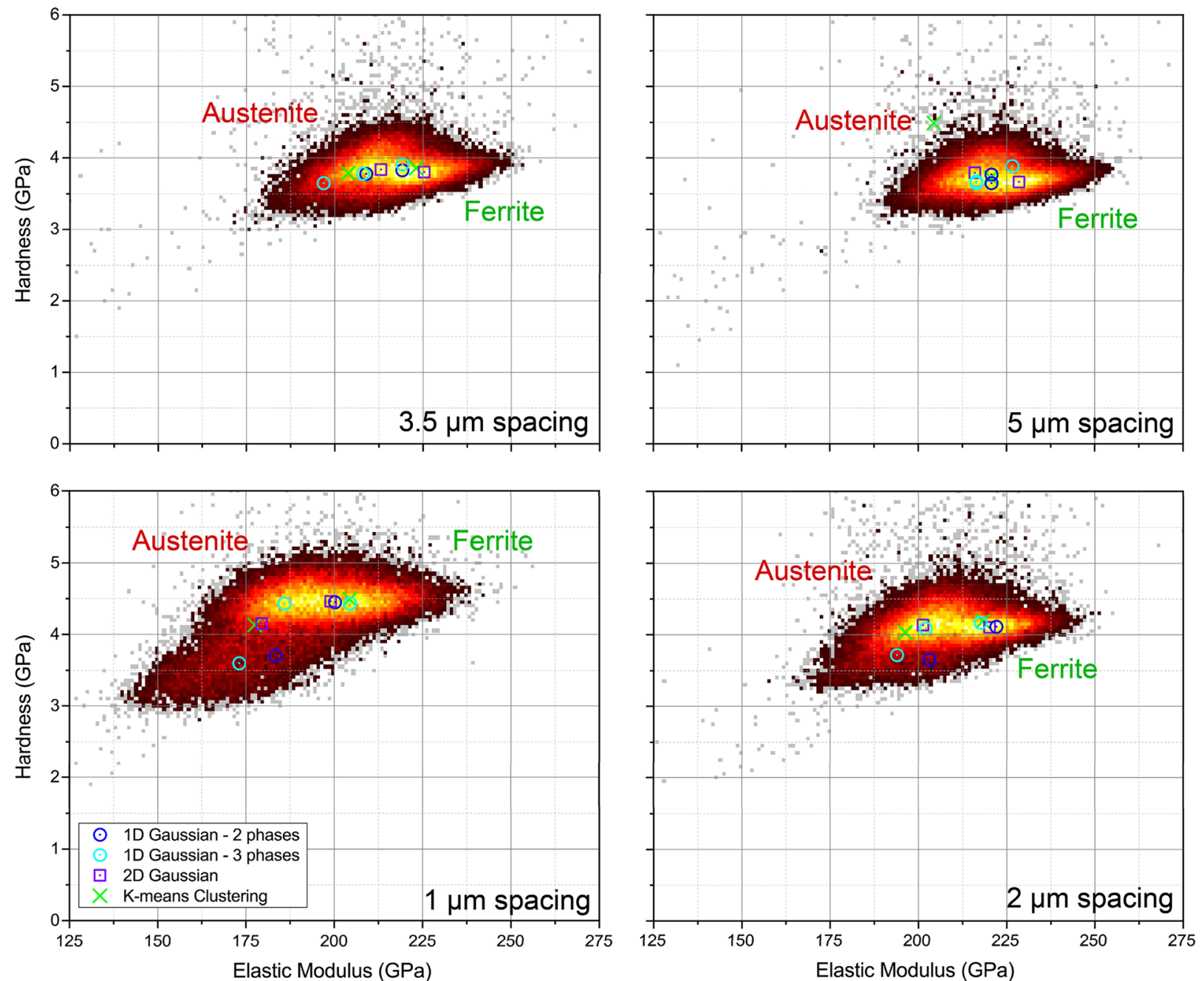

Figure 6: 2D histograms of hardness and elastic modulus data on the duplex stainless steel sample from each mapping spacing/depth increment with the locations of the fitting centers from each method labeled.

difficult in the DSS, as the indentation properties of the two alloys show significant overlap. This can be observed in the relatively low contrast and lack of sharp boundaries between the phases in the maps shown in Fig. 2, an even in the H/E ratio map in Fig. 4. This overlap is most clearly illustrated in Fig. 6, where the property distributions can be seen to overlap to such an extent that they present the appearance of a single, irregularly shaped peak in most of the $2 \mathrm{D}$ histograms. As such, this presents one of the biggest challenges for statistical deconvolution methods. With correlative analytical methods, particularly EBSD in this case, it is a relatively simple matter to separate the two phases and obtain their individual properties. Indeed, good correlation between $H / E$ ratio maps and EBSD phase maps has already been obtained on this material [14]. However, the focus of this work is to determine the relative effectiveness of various statistical methods alone.
If we examine the morphological evolution of the 2D histogram distributions in Fig. 6 as a function of indentation spacing, only slight changes can be observed. At first, we see a single elliptical distribution for the histogram at the finest spacing of $1 \mu \mathrm{m}$, which is elongated at a roughly constant hardness level of 4.5 GPa, that displays a significant tail towards the origin. This type of tail has been observed before in previous works $[14,24]$ to correspond to the influence of roughness or porosity on the hardness results. However, in this work, the high-level vibropolishing that the DSS sample underwent suggests that roughness is likely not a factor here. Instead, this tail, which originates from both phases according to the $H$ maps in Fig. 2, may arise from some grain orientations which favor sink-in or an effect from pop-in displacements at this low indentation depth. At $2 \mu \mathrm{m}$ spacing, a slight remnant of this tail can still be seen in the histogram, but the tail mostly disappears in the histograms 
TABLE 1: Summary of parameters extracted from indentation maps on Al-Cu eutectic and duplex stainless steel samples using conventional indentation (CSM) and various statistical methods.

\begin{tabular}{|c|c|c|c|c|c|c|c|c|c|c|c|}
\hline \multirow{3}{*}{ Spacing } & \multirow[b]{3}{*}{ Method } & \multicolumn{5}{|c|}{$\mathrm{Al}-\mathrm{Cu}$ eutectic } & \multicolumn{5}{|c|}{ Duplex stainless steel } \\
\hline & & \multirow[b]{2}{*}{ Phase } & \multicolumn{4}{|c|}{ Mechanical property } & \multirow[b]{2}{*}{ Phase } & \multicolumn{4}{|c|}{ Mechanical property } \\
\hline & & & $H$ & Std. Dev & $E$ & Std. Dev & & $H$ & Std. Dev & E & Std. Dev \\
\hline \multirow[t]{11}{*}{$1 \mu \mathrm{m}$} & CSM & Al & 1.87 & 0.08 & 84.8 & 2.4 & $a$ & 4.94 & 0.15 & 253.2 & 6.1 \\
\hline & & $\Theta$ & 6.81 & 0.23 & 128.6 & 2.5 & $\gamma$ & 4.71 & 0.03 & 213.3 & 7.2 \\
\hline & 1D Gaussian - 2 phases & Al & 1.34 & 0.33 & 75.6 & 10 & $a$ & 3.71 & 0.43 & 200.2 & 14 \\
\hline & & $\Theta$ & 5.15 & 1.01 & 94.8 & 6 & $\gamma$ & 4.45 & 0.21 & 183.2 & 14.8 \\
\hline & 1D Gaussian - 3 phases & Al & 1.28 & 0.23 & 74.8 & 9 & a & 3.6 & 0.36 & 204.4 & 11 \\
\hline & & Mixed & 3.11 & 1.27 & 83.1 & 15 & Mixed & 4.43 & 0.36 & 185.9 & 9.2 \\
\hline & & $\Theta$ & 5.49 & 0.69 & 94.5 & 6 & $\gamma$ & 4.43 & 0.39 & 173.1 & 14.2 \\
\hline & 2D Gaussian & $\mathrm{Al}$ & 1.29 & 0.44 & 71.1 & 17 & $a$ & 4.46 & 0.19 & 199 & 14.5 \\
\hline & & $\Theta$ & 5.4 & 0.85 & 92.1 & 19 & $\gamma$ & 4.15 & 0.38 & 179.4 & 12.2 \\
\hline & $\mathrm{K}$-means clustering & $\mathrm{Al}$ & 2.1 & - & 71.2 & - & $a$ & 4.13 & - & 204.4 & - \\
\hline & & $\theta$ & 5.12 & - & 93.8 & - & $\gamma$ & 4.49 & - & 177.5 & - \\
\hline \multirow[t]{11}{*}{$2 \mu \mathrm{m}$} & CSM & $\mathrm{Al}$ & 1.75 & 0.01 & 86.9 & 0.1 & $a$ & 4.32 & 0.17 & 231.9 & 6.1 \\
\hline & & $\Theta$ & 6.8 & 0.28 & 131 & 2.2 & $\gamma$ & 4.17 & 0.14 & 209.3 & 5.1 \\
\hline & 1D Gaussian -2 phases & $\mathrm{Al}$ & 1.39 & 0.29 & 73.5 & 8 & $a$ & 3.66 & 0.27 & 222 & 7.9 \\
\hline & & $\Theta$ & 4.84 & 1 & 95.5 & 9 & $\gamma$ & 4.11 & 0.19 & 203.1 & 11.6 \\
\hline & 1D Gaussian - 3 phases & Al & 1.33 & 0.22 & 74 & 8 & a & 3.72 & 0.26 & 217.6 & 9.3 \\
\hline & & Mixed & 2.66 & 0.74 & 94.5 & 7 & Mixed & 4.17 & 0.28 & 202 & 7.6 \\
\hline & & $\Theta$ & 4.95 & 0.89 & 96.5 & 10 & $\gamma$ & 4.09 & 0.13 & 193.9 & 10.2 \\
\hline & 2D Gaussian & $\mathrm{Al}$ & 1.35 & 0.49 & 73.9 & 16 & $a$ & 4.13 & 0.12 & 220.1 & 8.2 \\
\hline & & $\Theta$ & 4.89 & 0.87 & 94.6 & 24 & $\gamma$ & 4.1 & 0.21 & 201.3 & 9.5 \\
\hline & $\mathrm{K}$-means clustering & $\mathrm{Al}$ & 2.43 & - & 74.6 & - & $a$ & 4.03 & - & 218.2 & - \\
\hline & & $\Theta$ & 5.06 & - & 98.1 & - & $\gamma$ & 4.19 & - & 196.2 & - \\
\hline \multirow[t]{11}{*}{$3.5 \mu \mathrm{m}$} & CSM & $\mathrm{Al}$ & 1.64 & 0.06 & 86.5 & 1.4 & $a$ & 3.93 & 0.16 & 223.4 & 3.9 \\
\hline & & $\Theta$ & 6.64 & 0.07 & 130.2 & 2.6 & $\gamma$ & 3.98 & 0.14 & 208.2 & 4 \\
\hline & 1D Gaussian - 2 phases & $\mathrm{Al}$ & 2.33 & 0.78 & 94.3 & 13 & $a$ & 3.78 & 0.12 & 219.1 & 10.7 \\
\hline & & $\Theta$ & 6.38 & 0.63 & 112.2 & 6 & v & 3.83 & 0.27 & 208.9 & 10.9 \\
\hline & 1D Gaussian -3 phases & $\mathrm{Al}$ & 2.08 & 0.59 & 84.1 & 9 & $a$ & 3.65 & 0.23 & 219.2 & 9.9 \\
\hline & & Mixed & 3.42 & 0.91 & 99.1 & 7 & Mixed & 3.91 & 0.26 & 207.9 & 7.9 \\
\hline & & $\Theta$ & 6.46 & 0.56 & 112.8 & 6 & Y & 3.78 & 0.13 & 196.9 & 8.4 \\
\hline & 2D Gaussian & $\mathrm{Al}$ & 1.35 & 4.97 & 92 & 28 & $a$ & 3.84 & 0.21 & 225.5 & 6.9 \\
\hline & & $\Theta$ & 6.45 & 0.54 & 112 & 14 & $\gamma$ & 3.8 & 0.08 & 213.1 & 11.3 \\
\hline & K-means clustering & Al & 4.13 & - & 99.7 & - & $a$ & 3.79 & - & 223 & - \\
\hline & & $\Theta$ & & & & & $\gamma$ & 3.86 & - & 2.3 .8 & - \\
\hline \multirow[t]{11}{*}{$5 \mu \mathrm{m}$} & CSM & $\mathrm{Al}$ & 1.62 & 0.05 & 86.4 & 1.1 & $a$ & 3.8 & 0.08 & 220.1 & 2.5 \\
\hline & & $\Theta$ & 6.62 & 0.06 & 131.7 & 5.1 & $\gamma$ & 3.85 & 0.03 & 202.5 & 4.2 \\
\hline & 1D Gaussian - 2 phases & Al & 2.31 & 0.65 & 96.4 & 12 & $a$ & 3.77 & 0.25 & 220.7 & 10.5 \\
\hline & & $\Theta$ & 6.46 & 0.52 & 114.7 & 4 & v & 3.65 & 0.12 & 220.7 & 11.3 \\
\hline & 1D Gaussian -3 phases & $\mathrm{Al}$ & 2.21 & 0.56 & 87.2 & 9 & a & 3.65 & 0.11 & 226.6 & 9.2 \\
\hline & & Mixed & 4.12 & 0.75 & 101.5 & 8 & Mixed & 3.67 & 0.21 & 216.4 & 11.2 \\
\hline & & $\Theta$ & 6.56 & 0.41 & 115.1 & 4 & $\gamma$ & 3.89 & 0.23 & 216 & 7.7 \\
\hline & 2D Gaussian & $\mathrm{Al}$ & 2.1 & 1.38 & 100 & 28 & $a$ & 3.66 & 0.17 & 228.5 & 8.3 \\
\hline & & $\Theta$ & 6.6 & 0.44 & 115 & 10 & $\gamma$ & 3.79 & 0.11 & 216 & 8.4 \\
\hline & $\mathrm{K}$-means clustering & $\mathrm{Al}$ & 4.1 & - & 101.1 & - & a & 3.72 & - & 220.6 & - \\
\hline & & $\Theta$ & & & & & $\gamma$ & & & & \\
\hline
\end{tabular}

Merged cells indicate when a technique was unable to discriminate between the phases. 
from higher depth indentations. The irregular shape of the distribution is also observed to change in the histogram from $2 \mu \mathrm{m}$ spacing from a horizontal ellipsoid to a convolution of two, tilted elliptical distributions corresponding to the austenite and ferrite phases. The austenite, $\gamma$, phase is the larger and rounder of the two and is located in the upper left, corresponding to its higher hardness and lower modulus [14]. As noted previously, rounder distributions correspond to more isotropic phases, which is in accord with the FCC structure of the austenite phase. The ferrite, a, phase corresponds to the lobe which protrudes (particularly at higher depth indentation map histograms) in the lower right, corresponding to its higher modulus and lower hardness. This lobe can be seen to be strongly tilted along its $H / E$ ratio, which is in agreement with previous observations of anisotropic phases $[12,24]$.

Comparing the effectiveness of the statistical methods to a visual evaluation of the $2 \mathrm{D}$ histograms, we see a strong influence of the tails in the 1 and $2 \mu \mathrm{m}$ spacing histograms on the $1 \mathrm{D}$ Gaussian evaluation methods. The 2-phase version mistakenly identifies the tail as a phase and fits the second phase peak between the two-phase regions, while the 3 -phase version identifies the tail as the mixed phase and correctly finds the peaks of the $\alpha$ and $\gamma$ phases. The 2D Gaussian and $K$-means methods both also fit a single peak to the center of the convolution of the $\alpha$ and $\gamma$ phases and fit the other peak to a region corresponding to the tail. In the histogram from the $2 \mu \mathrm{m}$ spacing maps, other than the 1D Gaussian methods issue with the tail, all methods broadly identify the peaks of the two phases correctly with varying degrees of accuracy with 1D Gaussian-3-phase and 2D Gaussian methods giving the closest visual approximations. Similar trends are observed in the $3.5 \mu \mathrm{m}$ spacing histogram. All methods give reasonable approximations of the $\alpha$ and $\gamma$ phase peaks, though the third phase peak at low modulus values identified by the 1D Gaussian-3-phase method appears to correspond to nothing. At the highest depths, the histogram presents a very narrow distribution with significant overlap of the two phases, though the ferrite lobe is still prominent. This caused difficult for most methods. $K$-means only identified one joint peak for both $\alpha$ and $\gamma$ phases and placed the other minor peak outside the distribution. Both 1D Gaussian methods identified two closely spaced peaks near the center of the distribution, but the 3-phase version identified another point in the upper right of the distribution which is close to the $2 \mathrm{D}$ Gaussian value for the ferrite phase. Now, this point highlights the difficulty of interpreting two sets of $1 \mathrm{D}$ results in $2 \mathrm{D}$ space. The $1 \mathrm{D}$ Gaussian3 -phase method identifies 3 values for $H$ and $E$ each, but it is blind to the relation between the two. Therefore, six different sets of X,Y (in this case, $E, H$ ) coordinates could be determined from the output of the method with no indication as to which is correct! Without considering the data in two dimensions using a coupled analysis, a 2D histogram for visualization, or prior knowledge from conventional indentations or a correlative technique, it is impossible to guess the correct order. Using the 2D Gaussian method, which considers both dimensions, what appears to be the correct peak positions for the $\alpha$ and $\gamma$ phases can be identified.

\section{Conclusions}

The influence of indentation size and statistical deconvolution methods on the extracted phase properties of $\mathrm{Al}-\mathrm{Cu}$ eutectic and DSS samples have been studied. This is the first such comparison between deconvolution methods for high-speed nanoindentation data. In doing so, several different statistical analyses were implemented on a large dataset (500,000 imprints in total) obtained using high-speed nanoindentation mapping. The following conclusions could be drawn from this work.

- 2D histograms of hardness and elastic modulus values are an effective visual method of evaluation for qualitative interpretation of the mechanical properties of multiphase materials.

- Good agreement is generally observed between conventional nanoindentation results and indentation mapping results at most depth/spacing increments, excepting modulus on the DSS sample, including the indentation size effect in the duplex stainless steel. However, some disparity is still noted at shallow depths.

- The resolution of the different spacing/depth increment used in the mapping with respect to the individual phase properties was highlighted by the different microstructural length scales of the two materials tested. From the mechanical property maps and 2D histograms for Al-Cu eutectic sample, only the results from the $1 \mathrm{um}$ spacing increment were able to resolve the fine-scale aluminum phase within the $\mathrm{Al}_{2} \mathrm{Cu}$ dendrites. At all other spacings, only a mixed $\mathrm{Al}+\mathrm{Al}_{2} \mathrm{Cu}$ response could be measured, whereas in the duplex stainless steel, both phases could be clearly observed in the mechanical property maps at all investigation spacing/depth increments.

- The 1D Gaussian method achieved best results when incorporating a third phase to account for mixed phase indentations and other sources of error. However, a significant difficulty arises when combining fits for both $H$ and $E$ in $2 \mathrm{D}$ property space, as there is no way to interpret which of the three phases in one dimension corresponds to those in the other - without prior knowledge from another source, such as a $2 \mathrm{D}$ histogram or CSM indent in a known singlephase region.

- The rotated 2D Gaussian method was shown to be one of the more effective methods to determine the mechanical properties of each phase. However, this method demonstrated 
high sensitivity to the morphology of the samples (roughness and/or porosities). This might be remedied by fixing the rotation angles $2 \mathrm{D}$ Gaussian curves to peaks in the $H / E$ histogram.

- The $K$-mean clustering method was observed to be relatively ineffective when using only two fitting dimensions ( $H$ and $E)$, resulting in simple partitions of the data. Additional parameters must be utilized to enhance the accuracy of the method. It is suggested that $2 \mathrm{D}$ histogram plots also be used in parallel for quality control of the clustering algorithm. This method displays high sensitivity to error induced by surface roughness and mixed phase indentations.

\section{Materials and methods}

\section{Studied materials and sample preparation}

An Al-Cu eutectic alloy and a duplex stainless steel were investigated in this study. The Al-Cu eutectic alloy with a composition of $\mathrm{Al}-33 \mathrm{wt} \% \mathrm{Cu}$ was prepared from $\mathrm{Al}$ and $\mathrm{Cu}$ pure metals with purity of $99.95 \%$ (Zhongnuo New Materials Ltd.). The pure metals were melted using vacuum arc melting and then solidified in water-cooled copper crucible. The sample was then sectioned and metallographically prepared using standard methods described below.

The duplex stainless steel is a commercial EN 1.4462 DSS alloy, equivalent to AISI S31803, supplied by UGINE \& ALZ (ArcelorMittal Group, Luxembourg C, Luxembourg). It was provided in the form of plates of $300 \times 400 \mathrm{~mm}$ with $6 \mathrm{~mm}$ thickness, after an industrial hot rolling process. Detailed information about the chemical compositions and industrial hot rolling processing can be found elsewhere [14].

In order to perform massive indentation technique, having a flat and parallel surface is required. In doing so, the specimens were hot mounted using Bakelite powder, in order to acquire a plan parallel surface. Consequently, samples were precisely polished by chemo-mechanical polishing process with diamond paste down to $1 \mu \mathrm{m}$. Finally, in order to diminish the roughness and devalue the work hardening induced under polishing process, DSS sample was polished using a vibratory polisher unit (VibroMet 2, Buehler, USA) for $4 \mathrm{~h}$ with 0.03 silica solution.

\section{Microstructural characterization}

A field emission scanning electron microscope (FESEM, 7100F model, JEOL, Tokyo, Japan) equipped with electron backscatter diffraction (EBSD) camera was used to characterize the microstructures of studied samples. A phase map was obtained using a step size fixed at $250 \mathrm{~nm}$ at an acceleration voltage of $20 \mathrm{kV}$ and probe current of $9 \mathrm{nA}$. Volume fraction and grain size of each phase were determined using Channel 5.0 software (Oxford instruments PLC, Abingdon, UK).

\section{Nanoindentation}

Nanoindentation testing was carried out using iNano ${ }^{\circledR}$ system (KLA Instruments, Milpitas, CA, USA). A diamond Berkovich tip was calibrated using a standard fused silica sample. The NanoBlitz $3 \mathrm{D}$ technique was used for mapping. It offers rapid indenting process, wherein each indentation (positioning the indenter, reaching the surface, apply the load and retraction) would take less than $1 \mathrm{~s}$. NanoBlitz $3 \mathrm{D}$ technique performs the indentations under load control. Therefore, the applied load has to be adjusted somehow to achieve the desired penetration depth for each sample. Accordingly, decreasing grids using the target decrement feature were performed on both samples to establish load-depth relationships to determine what load at which to perform the indentation maps to achieve the correct depth for desired indentation spacing, based on the softer phase behavior. The necessity for choosing the softer phase's behavior for the load selection is highlighted in Fig. 7, where large disparity can be seen in the penetration depths between different phases. If only the average depth was used, rather than the softest, then indentations in the softer phases would overlap. This also implies that indentations in the harder phases will be performed to much shallower depths than the softer indents. Once the corresponding load for indentations for depths $\leq$ the target depth was determined, four grids of $200 \times 200$ indentations ( 40,000 indentations each) were carried out on each sample. For the Al-Cu eutectic sample, the grids were performed with applied loads of $0.4,1.4,4$, and $8 \mathrm{mN}$ for grid spacings of 1,2 , 3.5 , and $5 \mu \mathrm{m}$, respectively. For the duplex stainless steel, the grids were performed with applied loads of $1.25,4,10$, and $20 \mathrm{mN}$ for grid spacings of $1,2,3.5$, and $5 \mu \mathrm{m}$, respectively. This produced grids where the depth over the minimum indent spacing ratio was as follows: $<500 \mathrm{~nm} / 5 \mu \mathrm{m},<350 \mathrm{~nm} / 3.5 \mu \mathrm{m},<200 \mathrm{~nm} / 2 \mu \mathrm{m}$, and $<100 \mathrm{~nm} / 1 \mu \mathrm{m}$ for different matrices. These chosen ratios were fixed at minimum value of 10 , as suggested by Phani et al. [22], in order to prevent any overlapping/neighboring indent effects. Consequently, hardness $(H)$ and elastic modulus $(E)$ of each indentation were calculated using Oliver and Pharr method [1, 30].

Furthermore, the iNano ${ }^{\circ}$ system is equipped with continuous stiffness measurement (CSM) module. This feature could provide various information such as penetration depth, stiffness, hardness, and elastic modulus, during loading-unloading process for a single test. A minimum of 4 CSM indentations were performed in each constitutive phases of both samples. These sets of indentations provide us information on the evolution of mechanical properties ( $H$ and $E$ ) as a function of penetration depth for each phase. 

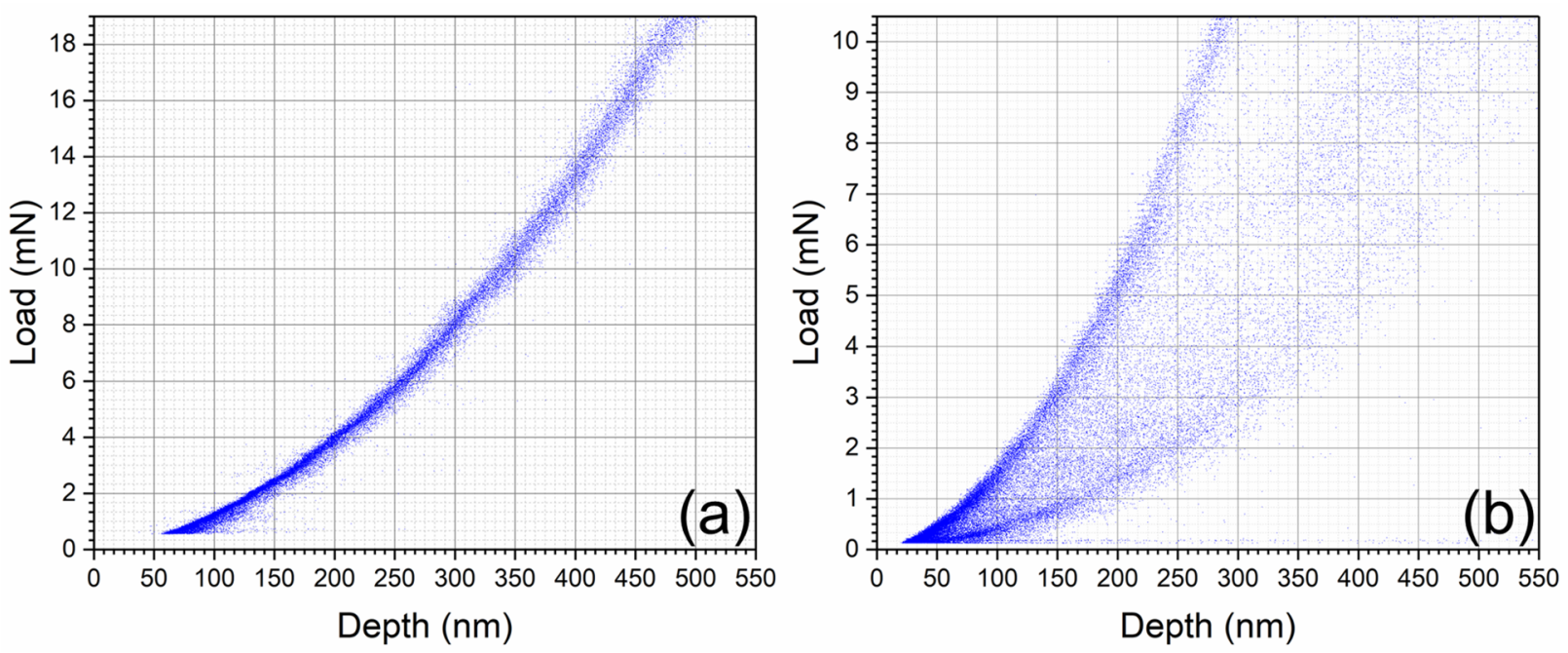

Figure 7: Load versus penetration depth plots obtained from decreasing grid of indentations performed on (a) DSS and (b) Al-Cu eutectic samples.

\section{Deconvolution methods of mechanical properties}

In the current study, the mechanical properties of each constitutive phases of investigated multiphase materials were evaluated using several statistical methods. The intrinsic $H$ and $E$ values of each phase were deconvoluted using different statistical analysis from the indentation maps performed at various depth/spacing increments. As follows, three different deconvolution methods were implemented on the indentation data.

\section{D Gaussian fitting-Ulm and Constantinides' method}

This methodology determines the single indentation properties ( $H$ and $E$ ) of the constitutive phases of multiphase materials using the statistical method (proposed by Ulm et al. [4, 17-19]) implemented on a data from large indentations arrays. In deconvolution process of indentation results, it is assumed that the distribution $\left(p_{i}\right)$ of intrinsic mechanical properties follows a Gaussian distribution described by Eq. 1 .

$$
p_{i}=\frac{1}{\sqrt{2 \pi \sigma_{i}^{2}}} \exp \left(-\frac{\left(x-\mu_{i}\right)^{2}}{2 \sigma_{i}^{2}}\right)
$$

where $\sigma_{i}$ is standard deviation and $\mu_{i}$ is the arithmetic mean value of desired property ( $H$ or $E$ ) for all indentation, $N_{i}$, in the phase $i$. Mean values of $\mu_{i}$ and $\sigma_{i}$ can be acquired from fitting cumulative distribution function using a sigmoid shape error function, written as Eq. 2.

$$
\mathrm{CDF}=\sum_{i} \frac{1}{2} f_{i} \operatorname{erf}\left(\frac{x-x_{i}}{\sqrt{2 \sigma_{i}}}\right)
$$

where $f_{i}$ is defined as the relative fraction occupied by each constitutive phase. In order to acquire reliable values, several restrictions need to be programmed during the deconvolution process. In this regard, the total volume fraction of constitutive phase was fixed at 1 , while the fitting process is set to finalize when the chi-square $\left(\chi^{2}\right)$ tolerance was less than $10^{-15}$, with an ultimate coefficient of determination $\left(R^{2}\right)$ of 0.9998 .

This statistical analysis has been successfully implemented for a variety of multiphase materials, which have heterogeneous phase distributions $[6,11,14,24,31]$.

\section{K-means cluster analysis}

K-means clustering is an algorithm which tends to partition ' $n$ ' observations into ' $k$ ' clusters, in which each observation pertains to a cluster with the closest mean, functioning as a prototype of the cluster. Each point of observation can only pertain to one cluster. The number of clusters $(K)$ can be considered as the number of phases in case of known multiphase systems. If the number of phases is unidentified, the optimum $K$ can be determined by iterating the algorithm for different $K$ number and choosing the best number with minimized error. $K$-means is an iterative refinement technique which initiates by generating random $K$ cluster center points, accordingly each data point will be assigned to the cluster with smallest Euclidean distance. It is important to note that this distance is evaluated purely numerically, so values (such as $E$ ) with larger numerical values would receive greater weighting if each dimension is not normalized to a similar numerical range. The algorithm iterates by switching the position of cluster center to a new spot, correspondingly the intra-cluster sum of squares of distances (Euclidean distance of points) will be minimized in each iteration. This procedure iterates until the cluster center is not updatable and intra-cluster distances cannot be reduced further. In this case, all experimental data ' $n$ ' (mechanical properties obtained by massive indentations) are segmented and assigned to a predetermined ' $K$ ' 
number of cluster once the $K$-means algorithm has converged. Several different dimensions can be used for this clustering $(H$, $E$, X, or Y position, depth, etc.), but for the most direct comparison with the other methods, only $H$ and $E$ were clustered in this work. However, Vignesh et al. [16] appears to have been able to successfully segment their data using only their $H$ values, since there was a significant spread in this property between their various phases. The current work highlights that the $K$-means technique is effectively material-dependent in that it can easily segment materials with quite different properties and no data overlap, but the algorithm struggles to segment phases with values can overlap. Actually, the $K$-means algorithm does not allow clusters to overlap and instead partitions the data at the midpoint between the cluster centers, which effectively shifts the cluster centers apart from the 'true' center. More information about the algorithm and the functionalities can be found in Refs. [16, 23, 32, 33].

\section{D Gaussian fitting}

Unlike above-mentioned methodologies which were relatively complicated, 2D Gaussian fitting can be considered as a simpler and discernable method to distinguish the mechanical properties of multiphase systems. It is well known that although $H$ and $E$ represent different mechanical phenomena, these two properties are interrelated for each constitutive phase and share similar anisotropy considering their parent crystal structure. Accordingly, by plotting both $H$ and $E$ values of each individual imprints, obtained from massive indentation testing as a $2 \mathrm{D}$ histogram of hardness against elastic modulus, both parameters can be fitted simultaneously. In doing so, a rotated, multivariate Gaussian function (Eq. 3) was implemented to fit the 2D histogram data for both investigated samples. For these two materials, two independent 2D Gaussians were iteratively fitted to the data using

$n=n_{0}+A \cdot e^{-\frac{1}{2}\left\{\left[\frac{\left(E-E_{\mathcal{C}}\right) \cos \theta-\left(H-H_{\mathcal{C}}\right) \sin \theta}{w_{\mathrm{E}}}\right]^{2}+\left[\frac{\left(E-E_{\mathcal{C}}\right) \sin \theta+\left(H-H_{\mathcal{C}}\right) \cos \theta}{w_{\mathrm{H}}}\right]^{2}\right\}}$

where $n$ is the number of indentations in a given $2 \mathrm{D}$ histogram bin, $n_{0}$ is an offset chosen to be 1 in this case to reduce the influence of outliers on the fitting, $A$ is the peak amplitude, $E_{c}$ and $H_{\mathrm{c}}$ are the center values for modulus and hardness of Gaussian peak, $\mathrm{w}_{\mathrm{E}}$ and $\mathrm{w}_{\mathrm{H}}$ are the widths (standard deviation) of the peak in modulus and hardness values, and $\theta$ is the angle of rotation in radians or $\arctan (H / E)$ of the peak. If the $H / E$ ratios for each phase were previously determined by some method, for example, using Ulm et al's method on $H / E$ values for the dataset, the values for $\theta$ could be fixed to expedite the fitting process. However, this was not done in this case. The Gaussian distribution rotation was allowed to rotate freely during iterations until the best fit was achieved.
In obtained 2D histograms (Figs. 5, 6), the color of each pixel represents the number of indentations that contained within a range of $\mathrm{H}$ and $\mathrm{E}$, which is defined as a $2 \mathrm{D}$ bin size. Intense shade bins correspond to a higher number of imprints contained within the bin. The clusters formed by accumulation of these intense bins could be related to each phase with different properties. Furthermore, some other parameters such as isotropic/anisotropic behavior of phases, roughness, and porosity can be evaluated through 2D histogram maps of $H$ vs $E$. This 2D histogram method has been validated for different multiphase system, as reported elsewhere $[12,14,24]$, but this is the first known application of 2D Gaussian fitting to nanoindentation mapping data.

\section{Acknowledgments}

H.B would like to gratefully acknowledge his Ph.D. supervisors, Prof. Luis Llanes, and Dr. Joan Josep Roa (CIEFMA, UPC) for their scientific supports and material supply. H.B also would like to thank Spanish Ministry of Science and Innovation for the financial supports through grant number PID2019-106631GBC41. J.M.W. would like to thank Dr. Bin Gan of the Beijing Key Laboratory of Advanced High Temperature Materials for providing the $\mathrm{Al}-\mathrm{Cu}$ eutectic alloy sample.

\section{Funding}

Open Access funding provided by ETH Zurich.

\section{Data availability}

The datasets generated during the current study are available from the corresponding author on reasonable request.

\section{Declarations}

Conflict of interest The authors have no conflicts of interest to declare that are relevant to the content of this article.

\section{Open Access}

This article is licensed under a Creative Commons Attribution 4.0 International License, which permits use, sharing, adaptation, distribution and reproduction in any medium or format, as long as you give appropriate credit to the original author(s) and the source, provide a link to the Creative Commons licence, and indicate if changes were made. The images or other third party material in this article are included in the article's Creative Commons licence, unless indicated otherwise in a credit line to the material. If material is not included in the article's Creative Commons licence and your intended use is not permitted by statutory regulation or exceeds the permitted use, you will need to obtain permission directly from the copyright holder. 
To view a copy of this licence, visit http://creativecommons.org/ licenses/by/4.0/.

\section{References}

1. W.C. Oliver, G.M. Pharr, An improved technique for determining hardness and elastic modulus using load and displacement sensing indentation experiments. J. Mater. Res. 7(6), 1564 (1992). https://doi.org/10.1557/JMR.1992.1564

2. W.D. Nix, H. Gao, Indentation size effects in crystalline materials: a law for strain gradient plasticity. J. Mech. Phys. Solids 46(3), 411 (1998). https://doi.org/10.1016/S0022-5096(97) 00086-0

3. C. Tromas, M. Arnoux, X. Milhet, Hardness cartography to increase the nanoindentation resolution in heterogeneous materials: application to a Ni-based single-crystal superalloy. Scr. Mater. 66(2), 77 (2012). https://doi.org/10.1016/j.scriptamat.2011.09.042

4. F.-J. Ulm, M. Vandamme, C. Bobko, J. Alberto Ortega, K. Tai, C. Ortiz, Statistical indentation techniques for hydrated nanocomposites: concrete, bone, and shale. J. Am. Ceram. Soc. 90(9), 2677 (2007). https://doi.org/10.1111/j.1551-2916.2007.02012.x

5. E.D. Hintsala, U. Hangen, D.D. Stauffer, High-throughput nanoindentation for statistical and spatial property determination. JOM 70(4), 494 (2018). https://doi.org/10.1007/ s11837-018-2752-0

6. J.J. Roa, P.S. Phani, W.C. Oliver, L. Llanes, Mapping of mechanical properties at microstructural length scale in WC-Co cemented carbides: assessment of hardness and elastic modulus by means of high speed massive nanoindentation and statistical analysis. Int. J. Refract Metal Hard Mater. 75, 211 (2018). https:// doi.org/10.1016/j.ijrmhm.2018.04.019

7. G. Guillonneau, M. Mieszala, J. Wehrs, J. Schwiedrzik, S. Grop, D. Frey, L. Philippe, J.-M. Breguet, J. Michler, J.M. Wheeler, Nanomechanical testing at high strain rates: new instrumentation for nanoindentation and microcompression. Mater. Des. 148, 39 (2018). https://doi.org/10.1016/j.matdes.2018.03.050

8. M. Sebastiani, R. Moscatelli, F. Ridi, P. Baglioni, F. Carassiti, High-resolution high-speed nanoindentation mapping of cement pastes: Unravelling the effect of microstructure on the mechanical properties of hydrated phases. Mater. Des. 97, 372 (2016). https://doi.org/10.1016/j.matdes.2018.03.050

9. J. Němeček, J. Lukeš, J. Němeček, High-speed mechanical mapping of blended cement pastes and its comparison with standard modes of nanoindentation. Mater. Today Commun. 23, 100806 (2020). https://doi.org/10.1016/j.mtcomm.2019.100806

10. M. de Nicolás, H. Besharatloo, J.M. Wheeler, M. de Dios, P. Alvaredo, J.J. Roa, B. Ferrari, L. Llanes, E. Gordo, Influence of the processing route on the properties of $\mathrm{Ti}(\mathrm{C}, \mathrm{N})-\mathrm{Fe} 15 \mathrm{Ni}$ cermets. Int. J. Refract Metal Hard Mater. 87, 105046 (2020). https://doi. org/10.1016/j.ijrmhm.2019.105046
11. H. Besharatloo, S. Gordon, T. Rodriguez-Suarez, A. Can, W.C. Oliver, L. Llanes, J.J. Roa, Small-scale mechanical properties of constitutive phases within a polycrystalline cubic boron nitride composite. J. Eur. Ceram. Soc. 39(16), 5181 (2019). https://doi. org/10.1016/j.jeurceramsoc.2019.08.023

12. J.M. Wheeler, Mechanical phase mapping of the Taza meteorite using correlated high-speed nanoindentation and EDX. J. Mater. Res. (2020). https://doi.org/10.1557/jmr.2020.207

13. C.M. Magazzeni, H.M. Gardner, I. Howe, P. Gopon, J.C. Waite, D. Rugg, D.E.J. Armstrong, A.J. Wilkinson, Nanoindentation in multi-modal map combinations: a Correlative Approach to Local Mechanical Property Assessment. arXiv preprint arXiv:2008.12267 (2020)

14. H. Besharatloo, M. Carpio, J.-M. Cabrera, A.M. Mateo, G. Fargas, J.M. Wheeler, J.J. Roa, L. Llanes, Novel mechanical characterization of austenite and ferrite phases within duplex stainless steel. Metals 10(10), 1352 (2020). https://doi.org/10. $3390 /$ met 10101352

15. K. Wieczerzak, J. Michler, J.M. Wheeler, S. Lech, R. Chulist, Ł Gondek, J. Czub, A. Hoser, N. Schell, P. Bała, An in situ and ex situ study of $\chi$ phase formation in a hypoeutectic Fe-based hardfacing alloy. Mater. Des. 188, 108438 (2020). https://doi. org/10.1016/j.matdes.2019.108438

16. B. Vignesh, W.C. Oliver, G.S. Kumar, P.S. Phani, Critical assessment of high speed nanoindentation mapping technique and data deconvolution on thermal barrier coatings. Mater. Des. 181, 108084 (2019). https://doi.org/10.1016/j.matdes.2019.108084

17. G. Constantinides, F.-J. Ulm, K. Van Vliet, On the use of nanoindentation for cementitious materials. Mater. Struct. 36(3 LB-Constantinides2003), 191 (2003). https://doi.org/10.1007/BF02479557

18. G. Constantinides, K.S. Ravi Chandran, F.J. Ulm, K.J. Van Vliet, Grid indentation analysis of composite microstructure and mechanics: principles and validation. Mater. Sci. Eng. A 430(1-2), 189 (2006). https://doi.org/10.1016/j.msea.2006.05.125

19. G. Constantinides, F.-J. Ulm, The nanogranular nature of C-S-H. J. Mech. Phys. Solids 55(1), 64 (2007). https://doi.org/10.1016/j. jmps.2006.06.003

20. B. Hilloulin, M. Robira, A. Loukili, Coupling statistical indentation and microscopy to evaluate micromechanical properties of materials: application to viscoelastic behavior of irradiated mortars. Cement Concr. Compos. 94, 153 (2018). https://doi. org/10.1016/j.cemconcomp.2018.09.008

21. G. Konstantopoulos, E.P. Koumoulos, C.A. Charitidis, Testing novel portland cement formulations with carbon nanotubes and intrinsic properties revelation: nanoindentation analysis with machine learning on microstructure identification. Nanomaterials 10(4), 645 (2020). https://doi.org/10.3390/nano10040645

22. P. SudharshanPhani, W.C. Oliver, A critical assessment of the effect of indentation spacing on the measurement of hardness and modulus using instrumented indentation testing. Mater. Des. 164, 107563 (2019). https://doi.org/10.1016/j.matdes.2018.107563 
23. J.A. Hartigan, M.A. Wong, Algorithm AS 136: a k-means clustering algorithm. J. R. Stat. Soc. C 28(1), 100 (1979). https://doi.org/ $10.2307 / 2346830$

24. Y. Xiao, H. Besharatloo, B. Gan, X. Maeder, R. Spolenak, J.M. Wheeler, Combinatorial investigation of $\mathrm{Al}-\mathrm{Cu}$ intermetallics using small-scale mechanical testing. J. Alloys Compd. 822, 153536 (2020). https://doi.org/10.1016/j.jallcom.2019.153536

25. T.T. Zhu, A.J. Bushby, D.J. Dunstan, Materials mechanical size effects: a review. Mater. Technol. 23(4), 193 (2008). https://doi. org/10.1179/175355508X376843

26. M. Sakai, The Meyer hardness: a measure for plasticity? J. Mater. Res. 14(9), 3630 (1999). https://doi.org/10.1557/JMR.1999.0490

27. D. Labonte, A.-K. Lenz, M.L. Oyen, On the relationship between indentation hardness and modulus, and the damage resistance of biological materials. Acta Biomater. 57, 373 (2017). https://doi.org/10. 1016/j.actbio.2017.05.034

28. Y.-T. Cheng, C.-M. Cheng, Relationships between hardness, elastic modulus, and the work of indentation. Appl. Phys. Lett. 73(5), 614 (1998). https://doi.org/10.1063/1.121873

29. T. Beirau, W.C. Oliver, C.E. Reissner, W.D. Nix, H. Pöllmann, R.C. Ewing, Radiation-damage in multi-layered zircon: mechanical properties. Appl. Phys. Lett. 115(8), 81902 (2019). https://doi.org/10.1063/1.5119207

30. W.C. Oliver, G.M. Pharr, Measurement of hardness and elastic modulus by instrumented indentation: advances in understanding and refinements to methodology. J. Mater. Res. 19(1), 3 (2004). https://doi.org/10.1557/jmr.2004.19.1.3

31. H. Besharatloo, M. de Nicolás, J.M. Wheeler, A. Mateo, B. Ferrari, E. Gordo, L. Llanes, J.J. Roa, Carbon addition effects on microstructure and small-scale hardness for $\mathrm{Ti}(\mathrm{C}, \mathrm{N})-\mathrm{FeNi}$ cermets. Int. J. Refract. Metal Hard Mater. 85, 105064 (2019). https://doi.org/10.1016/j.ijrmhm.2019.105064

32. A.G. Kusne, T. Gao, A. Mehta, L. Ke, M.C. Nguyen, K.-M. Ho, V. Antropov, C.-Z. Wang, M.J. Kramer, C. Long, I. Takeuchi, On-the-fly machine-learning for high-throughput experiments: search for rare-earth-free permanent magnets. Sci. Rep. 4(1), 6367 (2014). https://doi.org/10.1038/srep06367

33. Y. Chen, E. Hintsala, N. Li, B.R. Becker, J.Y. Cheng, B. Nowakowski, J. Weaver, D. Stauffer, N.A. Mara, High-throughput nanomechanical screening of phase-specific and temperaturedependent hardness in $\mathrm{Al}$ x FeCrNiMn high-entropy alloys. JOM 71(10), 3368 (2019). https://doi.org/10.1007/s11837-019-03714-2 